\title{
Peripheral artery disease in women
}

\author{
Şenol Yavuz $\odot$, Kadir Kaan Özsin๑, Umut Serhat Sanrı๑, Faruk Toktaş๑ \\ Department of Cardiovascular Surgery, University of Health Sciences, Bursa Yüksek İhtisas Training and Research Hospital, Bursa, \\ Turkey
}

\begin{abstract}
Peripheral artery disease (PAD) is a common disease among women and is expected to increase in the coming years. Diagnostic and therapeutic management of PAD in women is difficult due to their gender-related differences, comorbid factors, atypical symptoms, more functional disorders, the presence of advanced disease, being older age of the disease onset, smaller vessel diameter, and psychosocial factors. Especially due to the high prevalence of asymptomatic disease, late admission status and further disease on admission affect the success of the treatment negatively. By focusing more on PAD in women and more clinical studies, genderspecific differences can be identified. Hereby, there is a need to develop appropriate strategies to improve women's overall quality of life. In this review, we aimed to draw attention to the female gender with PAD, which is increasingly occurring.

Keywords: Peripheral artery disease, women, female gender, risk factor
\end{abstract}

$\mathbf{P}$ eripheral artery disease (PAD) occurs as the third most common result of systemic atherosclerosis after coronary artery disease and cerebrovascular disease. Lower limb PAD is estimated to affect about 8.5 million people in America and 202 million people worldwide over 40 years of age, which is increasingly leading to impaired functional disability and quality of life, and is a cardiovascular disease that is associated with myocardial infarction and stroke-related mortality [1]. It has been reported that major cardiovascular events, vascular interventions and re-hospital admissions are significantly higher in patients with PAD than in patients with coronary artery disease [2]. Patients with PAD have 5-6 times higher risk of morbidity or mortality than stroke and coronary artery disease [3].

The main risk factors for PAD are olderpeople, smoking, hypertension, diabetes and dyslipidemia [4, 5]. However, gender-specific risk factors have not been fully elucidated. In 2012, American Heart Association (AHA) highlighted that in the "Scientific Statement- A call the action: Women and Peripheral Artery Disease", the prevalence of PAD in adults over 40 years of age has increased and clinical awareness in women, focused treatment plans and research on PAD in women are needed [6]. Although it is stated that the prevalence of PAD is higher in men, recent evidence suggests that PAD is also common in women. Since PAD is an age-related disease, considering that women make up the majority of the elderly population, it can be said that PAD in women will increase rapidly in the near future. In addition, asymptomatic / subclinical disease rates are higher in women and most of them have atypical symptoms [7]. In addition, the psychological effects of the disease are more pronounced in women, and in a study, younger women under 65 years of age diagnosed with PAD have a 4-fold higher risk of depression than men [8]. Therefore, in this re- 
view, we aimed to draw attention to the female gender with PAD, which is increasingly occurring.

\section{PREVALENCE OF PAD IN WOMEN}

The prevalence of PAD in women has not been fully elucidated. Recently, there is no study in progress on a large population [6]. In the first studies on the prevalence of PAD, the disease was reported to be more common in men than in women and was accepted. However, these studies were conducted on symptomatic patients $[9,10]$. In a review, the prevalence of PAD has been reported to be between $3 \%$ and $29 \%$ among women 45 to 93 years of age, as in the male gender [9]. A recent review related to population-based studies reported that the mean prevalence of PAD is $15.6 \%$ in women and $13.4 \%$ in men [11]. Similarly, Sigvant et al. [12] reported contradictory results in women with a prevalence of PAD, that is similar to or higher than men. Population studies have showed a prevalence of PAD of $19.2 \%$ and $16.5 \%$ in women and men, respectively, which is not statistically significant. However, there was a significant gender-based recognition for asymptomatic PAD with a higher prevalence in women than in men (13\% vs. $9 \% ; p<0.03)$.

Compared to Western European countries, although total cholesterol levels are low in Turkey, risk factors such as increased smoking, increased frequency of obesity and metabolic syndrome, diabetes and hypertension are reported as important problems [13]. Although Turkey has a young population, the prevalence of atherosclerotic diseases and their associated mortality are highly observed. Therefore, although there is no large-scale study on $\mathrm{PAH}$ in Turkey, this rate is estimated to be higher [14].

\section{RISK FACTORS FOR PAD IN WOMEN}

General risk factors for PAD are similar among men and women, including age, smoking, diabetes mellitus, hypertension, and dyslipidemia. In women with PAD, the disease manifests itself, on average, 1020 years later than men [15]. PAD affects approximately $20-30 \%$ of women who are 70 years old or older $[10,16]$. Female sex hormones, especially estrogen, have been shown to protect women from cardiovascular disease until menopause [17]. Estrogen has been shown to participate in endothelial function, such as antioxidative defense, a reduction in cytokineinduced inflammation, and healing of vascular injury, including vasodilation and preservation of vascular tone [18]. The cardioprotective effects of estrogen can explain why women have cardiovascular disease 1020 years after men. Pregnancy loss associated with low estrogen concentrations in postmenopausal women has been associated with a three-fold higher risk of cardiovascular disease. Additionally, inflammatory markers, which are predictors for PAD, are higher [19-21]. The difference in PAD prevalence between men and women closes with age. Postmenopausal women have similar or even higher PAD prevalence rates than men. The outcomes of hormone replacement therapy on PAD in postmenopausal women are not clear.

The Women's Health Initiative (WHI) and the Heart and Estrogen / progestin Replacement (HERS) studies found that hormone replacement therapy did not make any difference in terms of PAH and coronary artery disease [22-24]. In contrast, the Rotterdam study and another prospective cohort study reported that hormone replacement therapy was associated with a decrease in PAD prevalence $[25,26]$. The Cardiovascular Health After Maternal Placental Syndrome (CHAMPS) study showed three-fold increased risk of PAD and two-fold increased risk of coronary artery and cerebrovascular disease in patients with maternal placental syndrome, including preeclampsia, gestational hypertension, placental abruption and placental infarction [27]. Although the possible cause is the underlying endothelial dysfunction, the mechanisms for this relationship are unclear.

Smoking is a greater risk factor for PAD in men, but diabetes and dysglycemia increase the risk of intermittent claudication in women 4 times [28, 29]. In patients with chronic renal failure, younger women $(<70$ years; mean age 56.5$)$ may have a higher PAD prevalence compared to paired men (1.53 times higher risk) [30]. Many studies have shown an association between obesity, C-reactive protein (CRP), osteopenia / osteoporosis and hypothyroidism, and PAD in women [31-35]. Risk factors specific to women are summarized in Table 1. 
Table 1. Risk factors for female gender-specific PAD

\begin{tabular}{lc}
\hline Risk Factors & Comments \\
\hline Menopause & Possible vasculoprotective effects \\
Oral contraceptives & Increased risk of venous and arterial thrombosis \\
Maternal placental syndrome & $\begin{array}{c}\text { Preeclampsia, gestational hypertension, placental } \\
\text { abruption and placental infarction }\end{array}$ \\
Depression & $<$ Age of 65,4 times higher risk than men \\
Elevated CRP & Higher levels of CRP than men \\
Osteopenia / Osteoporosis & Age-dependent \\
Hypothyroidism & This is controversial \\
\hline
\end{tabular}

$\mathrm{PAD}=$ Peripheral artery disease, $\mathrm{CRP}=\mathrm{C}$-reactive protein

\section{SCREENING AND SYMPTOMS}

The classic symptom of PAD is intermittent claudication, but not in all cases. Up to $40 \%$ of cases may not complain about leg symptoms and may occur with atypical symptoms. Women have higher subclinical, asymptomatic and atypical PAD rates [36, 37]. The American College of Cardiology / American Heart Association (ACC / AHA) guidelines recommend screening with the ankle-brachial index (ABI) for asymptomatic individuals over 65 and 5064 years old with diabetes and smoking [37]. In the Women's Health and Aging Study (WHAS), 35\% of 933 disabled women over 65 years were found to have $\mathrm{ABI}<0.9$ and were diagnosed with PAD. In the their study, they showed that $63 \%$ of patients diagnosed with PAD did not have classical exercise pain [38]. Asymptomatic PAD is common among older women. Most patients with PAD are asymptomatic or have atypical symptoms, and only $10 \%$ of patients present with classical claudication [1]. Women may be more asymptomatic or present with atypical symptoms. Atypical symptoms in women can be misinterpreted as arthritis, neuropathy or spinal stenosis, which is also evident in this population. There is a similarity with PAD severity between the level of physical activity and the measured $A B I$ value, but this may not apply to women [39]. In a study conducted at Northwestern University, it was found that women applying for PAD evaluation had more severe disease than men with $\mathrm{ABI}$ test [40]. Brevetti et al. [41] stated that women applying to the vascular laboratory are more likely to get Fontaine stage III or IV disease than men and have less classic symptoms of claudication than men. In a cohort study, the Walking and Leg Circulation Study (WALCS), among 460 PAD patients without critical limb ischemia, they found that the presence of atypical stress symptoms, which sometimes began to rest in 187 female patients, was twice as high as in men [42].

Women with PAD have more functional disorders than men. McDermott et al. [42] measured walking speed and distance, daily physical activity and performance scores in 273 PAD patients. They stated that despite similar disease severity in both genders, women experienced more impairment in lower limb function and strength, women had lower walking speeds, and achieved much shorter distances than men in a 6-minute walk. In a recent study in which PAD patients were followed up to 4 years, it was found that women with PAD had higher mobility loss and functional decline rates than men with PAD [43]. In a prospective WHAS cohort study, 847 women with low ABI $(<0.6)$ were predicted to have greater walkingrelated disorders [44]. PAD impairs the functional state more in women and women have a lower quality of life compared to men.

\section{DIAGNOSTIC METHODS}

A complete vascular history, presence of existing risk factors, and physical examination and control of the pulses are crucial for the diagnosis of PAD. Noninvasive diagnostic tests and objective evaluations are very valuable in detecting PAD due to limitations in physical examination. The most common first 
diagnostic test is resting ABI. ACC / AHA guidelines recommend screening with $\mathrm{ABI}$ for asymptomatic individuals over 65 and 50-64 years old with diabetes and smoking [37]. In a study of 1775 healthy individuals, ABI was found to be approximately 0.02 lower in women [45].

Physiological tests such as exercise ABI, toebrachial index, transcutaneous oxygen pressure, or skin perfusion pressure can be performed according to the clinical picture and resting ABI result [46]. Duplex ultrasound, magnetic resonance angiography (MRA), computed tomographic angiography, or invasive angiography are useful in providing anatomical location and severity of the disease. Currently, there is no large gender difference in the diagnostic sensitivity or accuracy of these tests [46].

Difficulties in diagnosis and treatment of genderspecific women in PAD are summarized in Table 2.

\section{TREATMENT OF PAD IN WOMEN}

Cardiovascular risk factor modification, exercise and medical therapy

The aim of symptomatic and asymptomatic PAD treatment should be primarily to decrease the progression of ischemic vascular events and to increase the quality of life and physical functionality. 2016-AHA / ACC guidelines recommend exercise program, smoking cessation, lipid lowering with statin therapy, blood pressure control with angiotensin receptor inhibitors, antiplatelet therapy, and aggressive diabetes management [1]. The main goals for both genders are to reduce cardiovascular morbidity and mortality and improve the quality of life of patients by improving limb-related symptoms. In addition to modification of risk factors, medical and revascularization therapy should be added to these targets for the treatment of claudication.

Although aggressive risk factor modification is the basis of treatment, the German REACH registry cohort study showed that patients with PAD alone were less likely to receive treatment with statins, angiotensin-converting enzyme inhibitors or antiplatelet agents compared to concomitant coronary artery disease patients [47]. In parallel with this study, the REACH (Reduction of Atherothrombosis for Continued Health) registry records showed that women with 8,322 PAD patients had significantly less optimal risk factor control than men [48]. This makes us think that the success of PAD treatment in women will be less than men, by taking the recommended risk factor control treatment of women with PAD less.

In a study investigating the effect of quitting smoking by Armstrong et al. [49], a five-year followup showed a marked reduction in all-cause mortality and amputation-free survival in both men and women. Sigvant et al. [50] reported that smoking for 10 years

Table 2. Difficulties in diagnosis and treatment for female gender-specific in PAD

\begin{tabular}{lc}
\hline Status & Comment \\
\hline Asymptomatic and atypical symptom & Delay in diagnosis \\
Higher prevalence of orthopedic diseases & $\begin{array}{c}\text { Arthritis and arthrosis } \\
\text { Delay in diagnosis }\end{array}$ \\
Presence of progressive disease at diagnosis & Low treatment success \\
Diagnosis at an advanced age & Low treatment success \\
Insufficient aggressive risk factor & Lower usage of antiplatelet agents, statins, \\
modification & angiotensin converting enzyme inhibitors \\
Failure to benefit from exercise training & Low treatment success \\
Small arterial diameter $(<7 \mathrm{~mm})$ & Low exercise tolerance \\
& Low treatment success \\
\hline
\end{tabular}

$\mathrm{PAD}=$ Peripheral artery disease 
in women is a risk factor for PAD, while it is 30 years in men. Ness et al. [51] described that smoking has a more detrimental effect on females than males in the presence of symptomatic PAD in older patients. In the light of these studies, we can say that smoking has a significantly more negative effect on PAH in women than men. In that case, stopping smoking seems to be an important element of PAH treatment compared to males.

Patients with PAD have limited exercise in their daily lives. There is evidence that a regular exercise training program is useful. It has been shown that lower limb exercise training increases the duration of claudication, increases the distance before claudication and increases the total walking distance [52]. In a meta-analysis examining 1200 people with stable leg pain, it was found that the maximum walking time improved significantly with exercise, with an overall improvement of $50 \%$ to $200 \%$ in walking ability [53]. In most randomized trials comparing supervised exercise training with pharmacological therapy or revascularization procedures, gender-specific analyzes were not performed, as female participants were less than $30 \%$ on average [6]. On the other hand, a study has shown that especially women with diabetic PAD have less responses to exercise rehabilitation programs, and this is partly due to further deterioration in calf muscle oxygen saturation during and after exercise. They also attributed this to lower leg strength, higher inflammation, higher oxidative stress level during ambulation, and lower hemoglobin saturation during insulin resistance [54].

Many studies have shown that the use of cholesterol-lowering therapy, especially statin, can not only improve symptoms of intermittent claudication but also increase walking distance from baseline [55, 56]. Although the proposal for statin use does not vary by gender, women with PAD are found to be less likely to receive statins.

Hypertension is an important risk factor for PAD and must be treated. Heart Outcomes Prevention Evaluation (HOPE) study [57] involving those with PAH and Ahimastos et al. [58] in their studies, they reported that in blood pressure control with ACE-I, cardiovascular mortality and morbidity decreased and painless walking distance improved. Therefore, ACE$\mathrm{I}$ is recommended as the first-line treatment for hypertensive patients with PAD. However, ACE-I use in women has some limitations such as fetal toxicity, multidrug-intolerance syndrome and breast cancer recurrence $[59,60]$.

Current guidelines recommend antiplatelet therapy in symptomatic PAD, but also recommend the use of antiplatelet therapy in patients with $\mathrm{ABI}<0.9$ and no symptoms. It can be administered with 75-325 $\mathrm{mg}$ of aspirin once a day or $75 \mathrm{mg}$ of clopidogrel once daily as a safe and effective alternative [1]. This recommendation does not vary by gender.

Among the available drugs, cilostazol, a phosphodiesterase inhibitor that inhibits platelet aggregation and has arterial vasodilating properties, is the drug with the most accurate evidence as a first-line pharmacological treatment in symptomatic PAD, including intermittent claudication [7]. In randomized clinical studies, it was concluded that Cilostazol improved both painless and maximum treadmill walking distance compared to placebo at a dose of 100 $\mathrm{mg}$ twice daily [61]. There were no different results in the treatment of cilostazol by gender.

\section{Surgical Revascularization}

The guidelines recommend revascularization in the presence of intermittent claudication that limits function despite optimal medical therapy. But although they have similar comorbidities with men, women have less revascularization procedures [6]. In the article "Scientific Statement- A call the action: Women and Peripheral Artery Disease" published by AHA in 2012, it was stated that women constitute only $32 \%$ of the participants in the PAD revascularization studies, and this shows that making treatment decisions is mostly with the results obtained from men [6]. Although the treatment options for both genders are similar, it was emphasized that women were recommended less surgical revascularization due to smaller vessel diameter, presence of advanced disease in diagnosis, advanced age of onset of disease, psychosocial factors and worse surgical results $[6,62$, 63]. In studies conducted, it was stated that the patency rates of the graft were lower in women in lower extremity surgical revascularization [6]. Although these reports suggest that there are low patency rates, especially in women treated with surgical bypass, no significant gender effects have been identified in patients treated with endovascular procedures, surgical 
bypass or a combination of these [64]. Similarly, another study reported that there were no gender differences in graft patency rates [65]. However, studies have found that female gender is an independent risk factor for postoperative wound complications (odds ratio: 1.376, 95\% CI: 1.076$1.757 ; \mathrm{p}=0.01)$. It has also been noted that wound complications increase the risk of limb loss, mortality, increased hospital stay, and decreased quality of life [66]. However, it has been suggested that women with lower extremity bypass are more likely to have hematoma, seroma and infection than men [67]. Despite the gender-related differences noted, the idea that revascularization option should be considered as a priority in women is strengthened because the amputation-free survival is similar in women and men [6].

\section{Endovascular Therapy}

It is likely that women are less likely to benefit from revascularization due to anatomical, comorbidity, advanced disease, age of onset of the disease, etc. In addition, it has been shown by studies that wound complications are more common in women. All these reasons raise the question of what is the place of endovascular treatments (stent, balloon angioplasty, atherectomy) in women.

According to the TransAtlantic Inter-Society Consensus (TASC), in iliac obstructive lesions for both men and women, endovascular approach with angioplasty and/or stenting is recommended as the first treatment option today, not only for patients with TASC A and B lesions, but also for patients with TASC C and D lesions, who are particularly poor candidates for open surgical repair [6].

As with surgical revascularization, caution should be exercised in endovascular therapy due to the presence of more aggressive atherosclerotic disease and smaller arterial diameter in the female sex. In several published studies [68-70], the results of iliac artery stents have been published, especially in women, but the results were insufficient as only bare metal stents were used. Piazza et al. [71] in their study investigating the effect of gender on endovascular treatment for iliac lesions, they reported that primary and secondary patency rates were significantly lower in women in the long-term follow-up, although they showd similar results in men and women in the early period. They determined that this was due to the fact that women had smaller arterial diameters and that the stent diameter was less than $<7 \mathrm{~mm}$ as a negative predictor. In the same study, it was emphasized that open surgery may still be a viable option in female patients with a target artery diameter of $<7 \mathrm{~mm}$ [71]. In another large patient-scale study, Ramkumar et al. [72] investigated the role of gender in determining the type of intervention in endovascular therapy. In this study, they found that women were less likely to undergo stenting or atherectomy than men, while they found higher rates of occlusion and re-intervention in women, especially in femoropopliteal arteries. Again in this study, they emphasized the effect of artery diameter on gender inequality in endovascular treatment.

As mentioned before, women with PAD are at an advanced age and more advanced disease stages, so any treatment in women is difficult. Matsi and Manninen [73] noted significantly higher bleeding complications (15\% vs. $6 \%$ ) in women undergoing percutaneous lower extremity angioplasty. In three state studies involving open surgery and endovascular treatments, a total of 372,692 patients, approximately $45 \%$ of whom were women, Vouyouka et al. [74] reported that women had higher mortality and morbidity rates than men after any type of vascular intervention.

\section{CONCLUSION}

The scarcity of research studies also prevents us from fully evaluating PAD results in female gender. Diagnosis and treatment management of PAD in women is difficult due to their gender-related differences. Especially due to the high prevalence of asymptomatic disease, late admission status and further disease on admission affect the success of the treatment negatively. As a result, the risk of mortality and morbidity increases in women. By focusing more on PAD in women and more clinical studies, genderspecific differences can be identified. Hereby, there is a need to develop appropriate strategies to improve women's overall quality of life.

\section{Authorship contributions}

Consept-Design: KKÖ, ŞY; Data collection: 
KKÖ, USS, FT; Analysis: KKÖ, FT, ŞY; Literature search: KKÖ, USS, FT; Writing: KKÖ, USS, ŞY; Critical review: ŞY.

\section{Conflict of interest}

The authors disclosed no conflict of interest during the preparation or publication of this manuscript.

\section{Financing}

The authors disclosed that they did not receive any grant during conduction or writing of this study

\section{REFERENCES}

1. Gerhard-Herman MD, Gornik HL, Barrett C, Barshes NR, Corriere MA, Drachman DE, et al. 2016 AHA/ACC Guideline on the Management of Patients with Lower Extremity Peripheral Artery Disease: Executive Summary. Vasc Med 2017;22:NP1NP43.

2. Steg PG, Bhatt DL, Wilson PW, D’Agostino R Sr, Ohman EM, Rother J, et al. One-year cardiovascular event rates in outpatients with atherothrombosis. JAMA 2007;297:1197-206.

3. Hirsch AT, Criqui MH, Treat-Jacobson D, Regensteiner JG, Creager MA, Olin JW, et al. Peripheral arterial disease detection, awareness, and treatment in primary care. JAMA 2001;286:131724.

4. Hirsch AT, Haskal ZJ, Hertzer NR, Bakal CW, Creager MA, Halperin JL, et al. ACC/AHA 2005 Practice Guidelines for the management of patients with peripheral arterial disease (lower extremity, renal, mesenteric, and abdominal aortic): a collaborative report from the American Association for Vascular Surgery/Society for Vascular Sur. Circulation 2006;113:463-654. 5. Chi Y-W, Jaff MR. Optimal risk factor modification and medical management of the patient with peripheral arterial disease. Catheter Cardiovasc Interv 2008;71:475-89.

6. Hirsch AT, Allison MA, Gomes AS, Corriere MA, Duval S, Ershow AG, et al. A call to action: women and peripheral artery disease: a scientific statement from the American Heart Association. Circulation 2012;125:1449-72.

7. Barochiner J, Aparicio LS, Waisman GD. Challenges associated with peripheral arterial disease in women. Vasc Health Risk Manag 2014;10:115-28.

8. Smolderen KG, Spertus JA, Vriens PW, Kranendonk S, Nooren M, Denollet J. Younger women with symptomatic peripheral arterial disease are at increased risk of depressive symptoms. J Vasc Surg 2010;52:637-44.

9. Higgins JP, Higgins JA. Epidemiology of peripheral arterial disease in women. J Epidemiol 2003;13:1-14.

10. Criqui MH, Fronek A, Barrett-Connor E, Klauber MR, Gabriel S, Goodman D. The prevalence of peripheral arterial disease in a defined population. Circulation 1985;71:510-5.

11. Vavra AK, Kibbe MR. Women and peripheral arterial disease. Womens Health (Lond) 2009;5:669-83.
12. Sigvant B, Wiberg-Hedman K, Bergqvist D, Rolandsson O, Andersson B, Persson E, et al. A population-based study of peripheral arterial disease prevalence with special focus on critical limb ischemia and sex differences. J Vasc Surg 2007;45:1185-91.

13. Tokgözoğlu L, Bariş Kaya E. Atherosclerotic vascular disease and risk factors in Turkey: from past to present. J Atheroscler Thromb 2008;15:286-91.

14. Karabay Ö, Karaçelik M, Yılık L, Tekin N, İriz AB, Kumdereli $\mathrm{S}$, et al. [Ischemic peripheral arterial disease: a screening survey]. Turk Gogus Kalp Dama 2012;20:450-7. [Article in Turkish]

15. Nguyen L, Liles DR, Lin PH, Bush RL. Hormone replacement therapy and peripheral vascular disease in women. Vasc Endovasc Surg 2004;38:547-56.

16. Newman AB, Siscovick DS, Manolio TA, Polak J, Fried LP, Borhani NO, et al. Ankle-arm index as a marker of atherosclerosis in the Cardiovascular Health Study. Cardiovascular Heart Study (CHS) collaborative research group. Circulation 1993;88:837-45.

17. El Khoudary SR. Gaps, limitations and new insights on endogenous estrogen and follicle stimulating hormone as related to risk of cardiovascular disease in women traversing the menopause: a narrative review. Maturitas 2017;104:44-53.

18. Miller VM, Duckles SP. Vascular actions of estrogens: functional implications. Pharmacol Rev 2008;60:210-41.

19. Atsma F, Bartelink ML, Grobbee DE, Rutten A, Bots ML, Prokop M, et al. Reproductive factors, metabolic factors, and coronary artery calcification in older women. Menopause 2008;15:899-904.

20. Parikh NI, Cnattingius S, Dickman PW, Mittleman MA, Ludvigsson JF, Ingelsson E. Parity and risk of later-life maternal cardiovascular disease. Am Heart J 2010;159:216-21.e6.

21. Cauley JA, Kassem AM, Lane NE, Thorson S; Osteoporotic Fractures in Men (MrOS) Study Research Group. Prevalent peripheral arterial disease and inflammatory burden. BMC Geriatr 2016;16:213.

22. Hsia J, Criqui MH, Rodabough RJ, Langer RD, Resnick HE, Phillips LS. Estrogen plus progestin and the risk of peripheral arterial disease: The Women's Health Initiative. Circulation 2004;109:620-6.

23. Hulley S, Grady D, Bush T, Furberg C, Herington D, Riggs $B$, et al. Randomized trial of estrogen plus progestin for secondary prevention of coronary heart disease in postmenopausal women. JAMA 1998;280:605-13.

24. Hsia J, Simon JA, Lin F, Applegate WB, Vogt MT, Hunninghake D, et al. Peripheral arterial disease in a randomized trial of estrogen with progestin in women with coronary heart disease.Circulation 2000;102:2228-32.

25. Westendorp I, Veld BA, Grobbee DE, Pols H, Meijer WT, Hofman A, et al. Hormone replacement therapy and peripheral arterial disease: The Rotterdam Study. Arch Intern Med 2000;160:2498-502.

26. Rockman CB, Maldonado TS, Jacobowitz GR, Adelman MA, Riles TS. Hormone replacement therapy is associated with a decreased prevalence of peripheral arterial disease in postmenopausal women. Ann Vasc Surg 2012;26:411-8. 
27. Ray JG, Vermeulen MJ, Schull MJ, Redelmeier DA. Cardiovascular health after maternal placental syndromes (CHAMPS): population-based retrospective cohort study. Lancet. 2005;366:1797-803.

28. Gerhard M, Baum P, Raby KE. Peripheral artieral-vascular disease in women: prevalence, prognosis, and treatment. Cardiology 1995;86:349-55.

29. Kannel WB, McGee DL. Update on some epidemiologic features of intermittent claudication: The Framingham Study. J Am Geriatr Soc 1985;33:13-8.

30. Wang GJ, Shaw PA, Townsend RR, Anderson AH, Xie D, Wang $\mathrm{X}$, et al. Sex differences in the incidence of peripheral artery disease in the chronic renal insufficiency cohort. Circ Cardiovasc Qual Outcomes 2016;9(2 Suppl 1):S86-93.

31. Lu B, Zhou J, Waring ME, Parker DR, Eaton CB. Abdominal obesity and peripheral vascular disease in men and women: a comparison of waist-to-thigh ratio and waist circumference as measures of abdominal obesity. Atherosclerosis 2010;208:2537.

32. Ridker PM, Cushman M, Stampfer MJ, Tracy RP, Hennekens $\mathrm{CH}$. Plasma concentration of C-reactive protein and risk of developing peripheral vascular disease. Circulation 1998;97:4258.

33. Lakoski SG, Cushman M, Criqui M, Rundek T, Blumenthal RS, D'Agostino RB Jr, et al. Gender and C-reactive protein: data from the Multiethnic Study of Atherosclerosis (MESA) cohort. Am Heart J 2006;152:593-8.

34. Aronow WS. Osteoporosis, osteopenia, and atherosclerotic vascular disease. Arch Med Sci 2011;7:21-6.

35. Paquet M, Pilon D, Tetrault JP, Carrier N. Protective vascular treatment of patients with peripheral arterial disease: guideline adherence according to year, age and gender. Can J Public Health 2010;101:96-100.

36. Benjamin EJ, Blaha MJ, Chiuve SE, Cushman M, Das SR, Deo R, et al. Heart disease and stroke statistics-2017 Update: a report from the American Heart Association. Ciruculation 2017; $135: 146-603$.

37. Jackson EA, Munir K, Schreiber T, Rubin JR, Cuff R, Gallagher KA, et al. Impact of sex on morbidity and mortality rates after lower extremity interventions for peripheral arterial disease. JACC 2014;63:2525-30.

38. McDermott MM, Fried L, Simonsick E, Ling S, Guralnik JM. Asymptomatic peripheral arterial disease is independently associated with impaired lower extremity functioning: the Women's Health and Aging Study. Circulation 2000;101:100712.

39. McDermott MM, Guralnik JM, Ferrucci L, Tian L, Liu K, Lias $\mathrm{Y}$, et al. Asymptomatic peripheral arterial disease is associated with more adverse lower extremity characteristics than intermittent claudication. Circulation 2008;117:2484-91.

40. Feinglass J, McDermott MM, Foroohar M, Pearce WH. Gender differences in interventional management of peripheral vascular disease: evidence from a blood flow laboratory population. Ann Vasc Surg 1994;8:343-9.

41. Brevetti G, Bucur R, Balbarini A, Melillo E, Novo S, Muratori I, et al. Women and peripheral arterial disease: same disease, different issues. J Cardiovasc Med 2008;9:382-8.
42. McDermott MM, Greenland P, Liu K, Criqui MH, Guralnik JM, Celic L, et al. Sex differences in peripheral arterial disease: leg symptoms and physical functioning. J Am Geriatr Soc 2003;51:222-8.

43. McDermott MM, Ferrucci L, Liu K, Guralnik JM, Tian L, Kibbe $\mathrm{M}$, et al. Women with peripheral arterial disease experience faster functional decline than men with peripheral arterial disease. J Am Coll Cardiol 2011;57:707-14.

44. McDermott MM, Ferrucci L, Simonsick EM, Balfour J, Fried $\mathrm{L}$, Ling $\mathrm{S}$, et al. The ankle brachial index and change in lower extremity functioning over time: the Women's Health and Aging Study. J Am Geriatr Soc 2002;50:238-46.

45. Aboyans V, CriquiMH, McClelland RL, Allison MA, McDermott MM, Goff DC Jr, et al. Intrinsic contribution of gender and ethnicity to normal ankle-brachial index values: the Multi-Ethnic Study of Atherosclerosis (MESA). J Vasc Surg 2007;45:319-27.

46. Patel T, Baydoun H, Patel NK, Tripathi B, Nanavaty S, Savani $\mathrm{S}$, et al. Peripheral arterial disease in women: The gender effect. Cardiovasc Revasc Med 2019 May 31.

47. Zeymer U, Parhofer KG, Pittrow D, Binz C, Schwertfeger M, Limbourg T, et al. Risk factor profile, management and prognosis of patients with peripheral arterial disease with or without coronary artery disease: results of the prospective German REACH registry cohort. Clin Res Cardiol 2009;98:249-56.

48. Cacoub PP, Abola MTB, Baumgartner I, Bhatt DL, Creager MA, Liau CS, et al. Cardiovascular risk factor control and outcomes in peripheral artery disease patients in the Reduction of Atherothrombosis for Continued Health (REACH) Registry. Atherosclerosis 2009;204:86-92.

49. Armstrong EJ, Wu J, Singh GD, Dawson DL, Pevec WC, Amsterdam EA, et al. Smoking cessation is associated with decreased mortality and improved amputation-free survival among patients with symptomatic peripheral artery disease. J Vasc Surg 2014;60:1565-71.

50. Sigvant B, Wiberg-Hedman K, Bergqvist D, Rolandsson O, Wahlberg E. Risk factor profiles and use of cardiovascular drug prevention in women and men with peripheral arterial disease. Eur J Cardiovasc Prev Rehabil 2009;16:39-46.

51. Ness J, Aronow WS, Ahn C. Risk factors for symptomatic peripheral arterial disease in older persons in an academic hospital-based geriatrics practice. J Am Geriatr Soc 2000;48:3124.

52. Parmenter BJ, Raymond J, Dinnen P, Singh MA. A systematic review of randomized controlled trials: walking versus alternative exercise prescription as treatment for intermittent claudication. Atherosclerosis 2011;218:1-12.

53. Watson L, Ellis B, Leng GC. Exercise for intermittent claudication. Cochrane Database Syst Rev 2008;(4):CD000990. 54. Gardner AW, Parker DE, Montgomery PS, Blevins SM, Nael $\mathrm{R}$, Afaq A. Sex differences in calf muscle hemoglobin oxygen saturation in patients with intermittent claudication. J Vasc Surg 2009;50:77-82.

55. Buchwald H, Bourdages HR, Campos CT, Nguyen P, Williams SE, Boen JR. Impact of cholesterol reduction on peripheral arterial disease in the Program on the Surgical Control of the Hyperlipidemias (POSCH). Surgery 1996;120:672-9. 
56. Pedersen TR, Kjekshus J, Pyörälä K, Olsson AG, Cook TJ, Musliner TA, et al. Effect of simvastatin on ischemic signs and symptoms in the Scandinavian simvastatin survival study (4S). Am J Cardiol 1998;81:333-5.

57. Yusuf S, Sleight P, Pogue J, Bosch J, Davies R, Dagenais G. Effects of an angiotensin-converting-enzyme inhibitor, ramipril, on cardiovascular events in high-risk patients. The Heart Outcomes Prevention Evaluation Study Investigators. New Eng J Med 2000;342:145-53.

58. Ahimastos AA, Lawler A, Reid CM, Blombery PA, Kingwell BA. Brief communication: ramipril markedly improves walking ability in patients with peripheral arterial disease: a randomized trial. Ann Intern Med 2006;144:660-4.

59. Macy E, Ho NJ. Multiple drug intolerance syndrome: prevalence, clinical characteristics, and management. Ann Allergy Asthma Immunol 2012;108:88-93.

60. Ganz PA, Habel LA, Weltzien EK, Caan BJ, Cole SW. Examining the influence of beta blockers and ACE inhibitors on the risk for breast cancer recurrence: results from the LACE cohort. Breast Cancer Res Treat 2011;129:549-56.

61. Regensteiner JG, Ware JE, McCarthy WJ, Zhang P, Forbes WP, Heckman J, et al. Effect of cilostazol on treadmill walking, community-based walking ability, and health-related quality of life in patients with intermittent claudication due to peripheral arterial disease: meta-analysis of six randomized controlled trials. J Am Geriatr Soc 2002;50:1939-46.

62. Egorova N, Vouyouka AG, Quin J, Guillerme S, Moskowitz A, Marin M, et al. Analysis of gender-related differences in lower extremity peripheral arterial disease. J Vasc Surg 2010;51:3729.

63. Hernandez-Vila EA. Peripheral arterial disease in women: the effect of gender on diagnosis and treatment. Tex Heart Inst J 2011;38:154-6.

64. Kashyap VS, Pavkov ML, Bena JF, Sarac TP, O’Hara PJ, Lyden SP, et al. The management of severe aortoiliac occlusive disease: endovascular therapy rivals open reconstruction. J Vasc Surg 2008;48:1451-7.

65. Feinglass J, Sohn MW, Rodriguez H, Martin GJ, Pearce WH.
Perioperative outcomes and amputation-free survival after lower extremity bypass surgery in California hospitals, 1996-1999, with follow-up through 2004. J Vasc Surg 2009;50:776-83.

66. Nguyen LL, Brahmanandam S, Bandyk DF, Belkin M, Clowes AW, Moneta GL, et al. Female gender and oral anticoagulants are associated with wound complications in lower extremity vein bypass: an analysis of 1404 operations for critical limb ischemia. J Vasc Surg 2007;46:1191-7.

67. Belkin M, Conte MS, Donaldson MC, Mannick JA, Whittemore AD. The impact of gender on the results of arterial bypass with in situ greater saphenous vein. Am J Surg 1995; 170:97-102.

68. Timaran CH, Stevens SL, Freeman MB, Goldman MH. External iliac and common iliac artery angioplasty and stenting in men and women. J Vasc Surg 2001;34:440-6.

69. Bechter-Hugl B, Falkensammer J, Gorny O, Greiner A, Chemelli A, Fraedrich G. The influence of gender on patency rates after iliac artery stenting. J Vasc Surg 2014;59:1588-96.

70. Krishnamurthy VN, Naeem M, Murphy TP, Cerezo J, Jordan $\mathrm{PG}$, Goldberg SH, et al. The effect of gender on outcomes of aortoiliac artery interventions for claudication. Clin Imaging 2016;40:96-100.

71. Piazza M, Squizzato F, Bassini S, Chincarini C, Grego F, Antonello M. The impact of female sex on the outcomes of endovascular treatment for iliac lesions. J Vasc Surg 2019 Nov 11.

72. Ramkumar N, Suckow BD, Brown JR, Sedrakyan A, MacKenzie T, Stone DH, et al. Role of sex in determining treatment type for patients undergoing endovascular lower extremity revascularization. J Am Heart Assoc 2019;8:e013088. 73. Matsi PJ, Manninen HI. Complications of lower-limb percutaneous transluminal angioplasty: a prospective analysis of 410 procedures on 295 consecutive patients. Cardiovasc Intervent Radiol 1998;21:361-6.

74. Vouyouka AG, Egorova NN, Salloum A, Kleinman L, Marin M, Faries PL, et al. Lessons learned from the analysis of gender effect on risk factors and procedural outcomes of lower extremity arterial disease. J Vasc Surg 2010;52:1196-202. 